\title{
The Relationship between Affective and Social Isolation among Undergraduate Students
}

\author{
Ahmad M. Alghraibeh ${ }^{1} \&$ Noof M. Bni Juieed ${ }^{2}$ \\ ${ }^{1}$ College of Education, Department of Psychology, King Saud University, Riyadh, KSA \\ ${ }^{2}$ Undergraduate student, College of Education, Education Policy, King Saud University, Riyadh, KSA \\ Correspondence: Ahmad M. Alghraibeh, Department of Psychology, King Saud University, PO Box 2458, \\ Riyadh, 11451, KSA. E-mail: aalghraibeh@ksu.edu.sa
}

Received: February 2, 2017

Accepted: September 11, 2017

Online Published: December 22, 2017

doi:10.5539/ies.v11n1p89

URL: https://doi.org/10.5539/ies.v11n1p89

\begin{abstract}
We examined the correlation between social isolation and affective isolation among 457 undergraduate students using a stratified cluster sampling technique. Participants comprised 221 men and 236 women, all of whom were either first- or fourth-year students enrolled in various majors at King Saud University. Means, standard deviations, Pearson (Spearman) correlations, z-values, a regression analysis, and an analysis of variance were used to address the study questions: (Are there significant differences $(\alpha \leqslant .05)$ in affective isolation per sex and academic level? Does the interaction between sex and academic level have a significant impact on affective isolation? What is the nature of the relationship between affective isolation and overall social isolation and its dimensions? Are there significant differences $(\alpha=.05)$ in the relationship per sex and academic level? Does affective isolation contribute towards the prediction of social isolation?). Significant differences regarding sex were found, as men showed more affective isolation. Significant differences were also found regarding the interaction between sex and academic level on affective isolation. However, the correlations between the social isolation dimensions of self-confidence, family containment and communication, and interaction with friends with affective isolation were negative. In addition, affective isolation predicted social isolation among students.
\end{abstract}

Keywords: academic level, affective isolation, sex, social isolation, student

\section{Introduction}

Scholars have long been interested in exploring the topic of isolation. This interest is typically attributed to the prevalence of isolation, particularly among adolescents, who tend to feel more isolated than people of other age groups (Grippo et al., 2007). This may contradict the extent of adolescents' social relations and wide connections; the lives of many are characterized by isolation and loneliness (Heaven, 2001). Humans are social by nature and tend to live in groups to feel safe, secure, peaceful, and to satisfy their needs for affiliation and derive social and moral standards from the group (Jung, 2014). Isolation is considered a social, emotional experience that is indicated by one's social relationships; some people measure it by an individual's relations with others, while others measure it by the weakness, strength, or degeneration of the relationships (Shaver \& Scott 1991).

Affective isolation is an evasive psychological trick that aims to relieve one of anxiety and tension, and helps one stay away from the pain caused by frustration, criticism, and insults (Jahoda, 1958). Affective isolation is used by some individuals to deal with pressure, based on their personalities; this technique aims to reduce obstacles that hinder individuals' adjustment or goal achievement (Mikulincer \& Florian 1995).

Adolescents' physical changes contribute towards feelings of isolation, reflect feelings of ambiguity about life and one's future, and are characterized by a loss of identity. These feelings influence adolescents' behavior, which is characterized by shame, laziness, inactivity, and the development of negative attitudes towards the social environment (Hall-Lande et al., 2007).

Many theories, such as psychoanalytic theory, have explained affective isolation. Proponents of this theory believe that affective isolation is a process of dissonance between one's psyche (i.e., id, ego, and super ego), which leads to maladjustment towards oneself and the surrounding environment. Freud (cited in Baumeister et al., 1998) refers affective isolation back to painful and unpleasant events and emotional shocks that individuals experience during their lives. Therefore, the affective isolation experience may be considered a defensive 
psychological mechanism that protects the personality from surrounding threats. In his self-theory, Adler posits that feelings of affective isolation are a result of deprivation of love, passion, and encouragement, which leads to feelings of inferiority (Adler, 2013; Bhugra, 2004). Furthermore, Jung (cited in Wedding, 2010) believes that affective isolation is a unique personal process that facilitates the development of one's relationships with others while attempting life adjustment. Levin (cited in Jung, 2014) explains that affective isolation is a state of incapacitating emotional imbalance and affects behavior so that it seems inconsistent or maladjusted to the real world. Maslow (cited in Jalal, 1985) referred to affective isolation as the inability to satisfy needs and to prove oneself because of a threatening environment that does not allow for natural development. Consequently, if individual needs are not satisfied, the situation becomes stressful and the individual's balance in relation to the environment is disturbed.

Social isolation is considered a stressful experience that affects individuals' personalities and their relationships with the social environment; it decreases social interaction and leads to withdrawal from social participation, affecting the individual personally and socially (Haines et al., 1993). It is a painful experience that results from individuals' inability to satisfy the needs of intimacy, closeness to others, and lack of social solidarity. For individuals experiencing social isolation, relationships are characterized by apathy, hopelessness, fearfulness, and rejection, and feeling isolated, detached from others, and not interacting with them (Weiss, 1973).

Social isolation may start at preschool age and persist until adolescence or even for life. There are many factors that adolescents worry and become miserable about. These include physical changes and the consequences of behavioral changes and the development of negative attitudes toward the social environment, especially when adolescents are misunderstood by adults and their physical changes are criticized (Tomaka et al., 2006).

Psychoanalytic theory interpreted social isolation as a state of inhibiting frustrating unconscious experiences of early childhood. The rejection and denial of painful experiences and inhibition of behavioral patterns that violate the social environment in turn lead to failure to enter intimate relationships with others (Jung, 2015). Behaviorists assert that there is conflict between processes leading to behavior and those leading to inhibition. The latter are a result of individuals' inability to abandon old conditional responses acquired in childhood, which lead to the development of inappropriate habits that do not facilitate an effective, successful life with others (Fenz \& Constantinou 2008).

Cognitive theorists believe that illogical beliefs and ideas contribute towards the emergence of illogical behavior and social isolation. Cognitive reconstruction is partly based on how individuals interpret the environment. According to cognitive theorists, negative adjustment refers to an individual's failure to comprehend and organize mental experiences; therefore, failure to adjust is a product of nonfunctional thinking (Wedding, 2010).

Chan, Dennis, and Funk (2008) confirmed the results of different theories. They indicated that the most common problems among undergraduate students are self-alienation and social isolation. The results showed that $80 \%$ of adolescents and youths feel lonely and lack feelings of belonging to society. Moreover, the level of social isolation highly correlated with sex, with girls showing higher levels of social isolation (Sanders et al., 2000).

Familial links have been revealed as well. The stronger the relationships between parents and their children, the more parents can protect children from feelings of isolation from society (Williamson 2004). Affective isolation has been found to be more prevalent among individuals who have lost their wives (Dugan \& Kivett, 1994). The results of different studies have concluded that general health, smoking, retirement, and having a deceased friend may predict social isolation (Nicholson 2010). In turn, social isolation predicts feelings of loneliness (Dugan \& Kivett, 1994; Murray, 2010).

Sanders et al. (2000) showed a positive relationship between average hours of Internet usage and social isolation; however, Hollos and Cowan (1973) also found that mental abilities may be negatively influenced by social isolation.

Other researchers have found a correlation between social isolation and diseases such as schizophrenia, which entails feelings of isolation and affective avoidance (Frampton \& Thomas, 2011). Feelings of loneliness and social isolation may also increase the predisposition towards high blood pressure among people of both sexes (Coyle, 2014).

As discussed above, isolation is a common phenomenon and may cause many problems among individuals of different age groups and sex. However, the psychological field lacks studies exploring the correlation between affective and social isolation among undergraduate students; therefore, this study tries to bridge this gap. The reviewed literature shows a diversity of results attributed to different sample sizes and locations; therefore, additional research is required. The current study is different from other studies because we identified 
correlations more accurately by examining sub-fields other than the overall results or using standardized tests and we explored the correlations and predictive abilities of social and affective isolation.

\subsection{Study Problem}

Revealing the correlation between affective and social isolation among undergraduate students at King Saud University requires deep analysis, to enable the elucidation of the magnitude of the phenomenon, its reality, and the extent of its prevalence among students. Feelings of isolation may have a negative impact on the educational process, lead to a weakened sense of responsibility, indifference, lack of self-esteem, and dropping out. The accumulation of these problems or failure to treat them may lead to less satisfaction with one's studies, motivation, efficiency, and self-esteem, and may result in personality disorders (Platt, 2009). The research problem stems from sensitivity during adolescence, an age characterized by many psychological and social issues, building a future requiring substantial effort and a readiness to accomplish one's goals, and openness in one's relationships with others. The stage may result in confusion, impair development, or may facilitate self-realization and personal refinement.

Based on the reviewed literature and efforts exhausted by the Ministry of Education (Al-Ghamdi, 2011) to develop the educational fields, the authors attempted to explore the problem and identify its causes. This was also due to the authors having noticed a few cases of maladjustment and isolation in their classes; some students had poor social skills, which prompted the authors to examine the students' contexts and to explore their affective isolation and its correlation with social isolation. Specifically, we attempted to answer the following questions:

1) Are there significant differences $(\alpha \leqslant .05)$ in affective isolation per sex and academic level? Does the interaction between sex and academic level have a significant impact on affective isolation?

2) What is the nature of the relationship between affective isolation and overall social isolation and its dimensions? Are there significant differences $(\alpha=.05)$ in the relationship per sex and academic level?

3) Does affective isolation contribute towards the prediction of social isolation?

\subsection{Importance of the Study}

This study shed light on the state of undergraduate students at King Saud University, which may hinder their scientific and practical development. Understanding students' feelings of isolation is the first step toward resolving isolation problems. Studying the relationship between affective isolation and social isolation outlines a means of preventing isolation and promoting methods to treat it.

This study draws attention to the psychological status of students, and urges developers of educational counseling and guidance programs in the Ministry of Higher Education to overcome difficulties, achieve psychological compatibility, and strive towards the positive development of students' personalities to enhance self-appreciation and create a positive psychological and social environment for them. The study will inform the design and assessment of counseling programs. Isolation may place individuals at risk and requires effort towards diagnosis, as it is an internal emotional state that is not easily observed by others. This renders it a concerning phenomenon that requires psychological and social intervention, coupled with attempts towards providing positive solutions that could effectively facilitate social and affective adjustment among students.

\subsection{Procedural Definitions}

Affective isolation is a method of treating stress that some individuals resort to, based on their personality style. It aims to ease obstacles that hinder adjustment balance or goal achievement (Mikulincer \& Florian, 1995). Operationally, it is defined as the score that a student obtains on the Affective Isolation Test used in this study.

Social isolation is an unpleasant experience that causes a sense of undesirable pain to the individual; it represents subjective awareness of the lack of social relationships in quantity (the individual does not have enough friends) and quality (the individual lacks intimate relationships with others) (Weiss, 1973). Operationally, it is defined as the score that a student obtains on the Social Isolation Test used in this study.

\subsection{Study Variables}

We examined the following variables: social isolation, affective isolation, sex, and academic level.

\section{Method}

A descriptive, correlative approach was used in this study. 


\subsection{Sample}

A stratified random cluster sample of 457 (221 men, 236 women) undergraduate students enrolled at King Saud University in the academic year 2015/2016 participated in the study. Participants were first- and fourth-year students enrolled in various majors (see Table 1 for details).

Table 1. The sample distribution based on sex, academic level, and major

\begin{tabular}{|c|c|c|c|c|c|c|}
\hline \multirow{2}{*}{ Sex } & \multirow{2}{*}{ Academic level } & \multirow{2}{*}{ Statistics } & \multicolumn{3}{|c|}{ Major } & \multirow{2}{*}{ Overall } \\
\hline & & & Humanitarian & Health & Scientific & \\
\hline \multirow{6}{*}{ Male } & \multirow{2}{*}{ First-year } & Number & 29 & 38 & 47 & 114 \\
\hline & & Percentage & $13.1 \%$ & $17.2 \%$ & $21.3 \%$ & $51.6 \%$ \\
\hline & \multirow{2}{*}{ Fourth-year } & Number & 30 & 31 & 46 & 107 \\
\hline & & Percentage & $13.6 \%$ & $14.0 \%$ & $20.8 \%$ & $48.4 \%$ \\
\hline & \multirow{2}{*}{ Total } & Number & 59 & 69 & 93 & 221 \\
\hline & & Percentage & $26.7 \%$ & $31.2 \%$ & $42.1 \%$ & $100.0 \%$ \\
\hline \multirow{6}{*}{ Female } & \multirow{2}{*}{ First-year } & Number & 31 & 27 & 57 & 115 \\
\hline & & Percentage & $13.1 \%$ & $11.4 \%$ & $24.2 \%$ & $48.7 \%$ \\
\hline & \multirow{2}{*}{ Fourth-year } & Number & 22 & 46 & 53 & 121 \\
\hline & & Percentage & $9.3 \%$ & $19.5 \%$ & $22.5 \%$ & $51.3 \%$ \\
\hline & \multirow{2}{*}{ Total } & Number & 53 & 73 & 110 & 236 \\
\hline & & Percentage & $22.5 \%$ & $30.9 \%$ & $46.6 \%$ & $100.0 \%$ \\
\hline
\end{tabular}

\subsection{Instruments}

We utilized two instruments: the Affective Isolation Test and the Social Isolation Test.

\subsubsection{Affective Isolation Test}

The test was developed by Khader (2009); it includes 21 items and measures the level of affective isolation. Participants respond to the test items using a 4-point Likert scale ranging from "rarely applies" to "totally applies." The students were required to identify the degree of practicing the behavior described in each item. Based on the test, affective isolation was classified into four levels: "very weak" (1-1.75), "weak" (1.76-2.50), "high" (2.51-3.25), and "very high" (3.26-4).

To ensure validity, nine professors reviewed the initial version of the test and evaluated the test items in terms of their suitability to the aim. Their observations were considered in the modification of the test. Generally, it was agreed that the items matched the purpose of the study, and the test had an acceptable validity degree of $79 \%$.

The test's reliability was calculated based on the responses provided by a pilot sample $(\mathrm{N}=20)$ of undergraduate students. The item-total correlation coefficients ranged from .36 to .70 (Table 2).

Table 2. Correlation coefficient of affective isolation based on test dimensions and the overall test

\begin{tabular}{cccccc}
\hline Item & Item-total correlation coefficient & Item & Item-total correlation coefficient & Item & Item-total correlation coefficient \\
\hline 1 & $.59^{* *}$ & 8 & $.70^{* *}$ & 15 & $.47^{* *}$ \\
2 & $.49^{* *}$ & 9 & $.61^{* *}$ & 16 & $.36^{*}$ \\
3 & $.64^{* *}$ & 10 & $.51^{* *}$ & 17 & $.49^{* *}$ \\
4 & $.57^{* *}$ & 11 & $.51^{* *}$ & 18 & $.51^{* *}$ \\
5 & $.61^{* *}$ & 12 & $.52^{* *}$ & 19 & $.55^{* *}$ \\
6 & $.59^{* *}$ & 13 & $.51^{* *}$ & 20 & $.42^{* *}$ \\
7 & $.45^{* *}$ & 14 & $.47^{* *}$ & 21 & $.49^{* *}$ \\
\hline
\end{tabular}

Note. ${ }^{*} \mathrm{p}<.05, * * \mathrm{p}<.01$.

Table 2 indicates that all the correlation coefficients were suitable and acceptable; therefore, none of the items were removed.

To calculate the Affective Isolation Test's reliability, the authors used Cronbach's alpha to compute the internal consistency of the pilot sample's responses. A value of .81 was obtained and considered adequate. The instrument was retested after an interval of two weeks to determine its test-retest reliability. Pearson's correlation 
analysis yielded a score of 89 .

\subsubsection{Social Isolation Test}

The test was adopted from Saleh's (2012) test and consists of 80 items distributed on seven dimensions of self-awareness and confidence in others' acceptance (11 items), self-confidence (11 items), family containment and communication (11 items), interaction with friends (12 items), affective and social skills (17 items), friendly withdrawal and avoidance (10 items), and emotional emptiness (9 items). Negative items responses were graded on a 5-point Likert scale: 5 = "strongly agree," 4 = "agree," 3 = "neutral," 2 = "disagree," and 1 = "strongly disagree." For the positive items, scores' levels were inverted. The negative test items were categorized into five levels: (1-1.80) "very low," (1.81-2.60) "low," (2.61-3.40) "moderate," (3.41-4.20) high, and (4.21-5) "very high." These levels were also inverted for positive items.

To ensure the test's validity, nine professors reviewed the initial version of the test and provided observations on the test items in terms of suitability to the aim, and their observations were considered in the modification of some items. Generally, it was agreed that the items matched the purpose of the study; the test had an acceptable validity score of $85 \%$. Test reliability was computed. The correlation coefficient with dimension ranged from .32 to .72 (Table 3 ). The item-total correlation coefficients ranged from .33 to .68 (Table 4 ).

Table 3. Correlation coefficients for social isolation items, dimensions, and the overall test

\begin{tabular}{|c|c|c|c|c|c|c|c|c|c|c|c|}
\hline Item & $\begin{array}{c}\text { Correlation } \\
\text { coefficient } \\
\text { with } \\
\text { dimension }\end{array}$ & $\begin{array}{l}\text { Item-total } \\
\text { correlation } \\
\text { coefficient }\end{array}$ & Item & $\begin{array}{c}\text { Correlation } \\
\text { coefficient } \\
\text { with } \\
\text { dimension }\end{array}$ & $\begin{array}{c}\text { Item-total } \\
\text { correlation } \\
\text { coefficient }\end{array}$ & Item & $\begin{array}{c}\text { Correlation } \\
\text { coefficient } \\
\text { with } \\
\text { dimension }\end{array}$ & $\begin{array}{l}\text { Item-total } \\
\text { correlation } \\
\text { coefficient }\end{array}$ & Item & $\begin{array}{c}\text { Correlation } \\
\text { coefficient } \\
\text { with } \\
\text { dimension }\end{array}$ & $\begin{array}{l}\text { Item-total } \\
\text { correlation } \\
\text { coefficient }\end{array}$ \\
\hline A1 & $.45^{* *}$ & $.42 * *$ & B11 & $.46^{* *}$ & $.33^{*}$ & D9 & $.56^{* *}$ & $.44 * *$ & E17 & $.55^{* *}$ & $.52 * *$ \\
\hline $\mathrm{A} 2$ & $.60^{* *}$ & $.52 * *$ & $\mathrm{C} 1$ & $.46^{* *}$ & $.39 *$ & D10 & $.68^{* *}$ & $.40^{*}$ & F1 & $.53 * *$ & $.43^{* *}$ \\
\hline A3 & $.42 * *$ & $.36^{*}$ & $\mathrm{C} 2$ & $.45^{* *}$ & $.49 * *$ & D11 & $.38^{*}$ & $.55^{* *}$ & F2 & $.46^{* *}$ & $.47 * *$ \\
\hline A4 & $.59 * *$ & $.43 * *$ & $\mathrm{C} 3$ & $.52 * *$ & $.33^{*}$ & D12 & $.36^{*}$ & $.47 * *$ & F3 & $.52 * *$ & $.54 * *$ \\
\hline A5 & $.42 * *$ & $.41^{* *}$ & $\mathrm{C} 4$ & $.50 * *$ & $.38 *$ & E1 & $.61^{* *}$ & $.50 * *$ & F4 & $.50 * *$ & $.43 * *$ \\
\hline A6 & $.46^{* *}$ & $.40^{*}$ & C5 & $.63^{* *}$ & $.45^{* *}$ & E2 & $.39 *$ & $.37 *$ & F5 & $.52 * *$ & $.40 * *$ \\
\hline A7 & $.70 * *$ & $.48 * *$ & C6 & $.46^{* *}$ & $.47 * *$ & E3 & $.56^{* *}$ & $.47 * *$ & F6 & $.52 * *$ & $.35^{*}$ \\
\hline A8 & $.37 *$ & $.46^{* *}$ & $\mathrm{C} 7$ & $.46^{* *}$ & $.40^{*}$ & E4 & $.54 * *$ & $.55^{* *}$ & F7 & $.52 * *$ & $.38^{*}$ \\
\hline A9 & $.73 * *$ & $.46^{* *}$ & $\mathrm{C} 8$ & $.32 *$ & $.40^{*}$ & E5 & $.50 * *$ & $.40^{*}$ & F8 & $.63^{* *}$ & $.48 * *$ \\
\hline A 10 & $.68 * *$ & $.44^{* *}$ & C9 & $.53 * *$ & $.47^{* *}$ & E6 & $.43^{* *}$ & $.33^{*}$ & F9 & $.50 * *$ & $.35^{*}$ \\
\hline A11 & $.60 * *$ & $.48^{* *}$ & $\mathrm{C} 10$ & $.52 * *$ & $.43 * *$ & E7 & $.58 * *$ & $.44 * *$ & F10 & $.61^{* *}$ & $.57 * *$ \\
\hline B1 & $.46^{* *}$ & $.37^{*}$ & C11 & $.51^{* *}$ & $.45^{* *}$ & E8 & $.55^{* *}$ & $.49^{* *}$ & G1 & $.54 * *$ & $.45^{* *}$ \\
\hline B2 & $.63^{* *}$ & $.47 * *$ & D1 & $.55^{* *}$ & $.45^{* *}$ & E9 & $.54 * *$ & $.50 * *$ & G2 & $.52 * *$ & $.47^{* *}$ \\
\hline B3 & $.61^{* *}$ & $.58 * *$ & D2 & $.47^{* *}$ & $.34 *$ & E10 & $.57 * *$ & $.56^{* *}$ & G3 & $.65^{* *}$ & $.51 * *$ \\
\hline B4 & $.53 * *$ & $.48^{* *}$ & D3 & $.51 * *$ & $.33^{*}$ & E11 & $.48 * *$ & $.51 * *$ & G4 & $.73 * *$ & $.68 * *$ \\
\hline B5 & $.67 * *$ & $.41 * *$ & D4 & $.57 * *$ & $.34 *$ & E12 & $.33 *$ & $.50 * *$ & G5 & $.72 * *$ & $.60 * *$ \\
\hline B6 & $.72 * *$ & $.49^{* *}$ & D5 & $.36^{*}$ & $.44 * *$ & E13 & $.44 * *$ & $.43^{* *}$ & G6 & $.70^{* *}$ & $.62 * *$ \\
\hline B7 & $.60^{* *}$ & $.42 * *$ & D6 & $.45^{* *}$ & $.44^{* *}$ & E14 & $.49^{* *}$ & $.36 *$ & G7 & $.54 * *$ & $.58 * *$ \\
\hline B8 & $.61^{* *}$ & $.46^{* *}$ & D7 & $.57 * *$ & $.37^{*}$ & E15 & $.58 * *$ & $.51 * *$ & G8 & $.67^{* *}$ & $.60 * *$ \\
\hline B9 & $.52 * *$ & $.43^{* *}$ & D8 & $.51^{* *}$ & $.34 *$ & E16 & $.57 * *$ & $.52 * *$ & G9 & $.68 * *$ & $.65^{* *}$ \\
\hline B10 & $.55^{* *}$ & $.55^{* *}$ & & & & & & & & & \\
\hline
\end{tabular}

Note. ${ }^{*} \mathrm{p}<.05, * * \mathrm{p}<.01$. 
Table 4. Correlation coefficients of the dimensions and affective isolation test

\begin{tabular}{|c|c|c|c|c|c|c|c|c|}
\hline $\begin{array}{l}\text { Dimensions of } \\
\text { Affective } \\
\text { Isolation Test }\end{array}$ & $\begin{array}{c}\text { Self-awareness } \\
\text { and confidence } \\
\text { in others' } \\
\text { acceptance }\end{array}$ & Self-confidence & $\begin{array}{c}\text { Family } \\
\text { containment and } \\
\text { communication }\end{array}$ & $\begin{array}{c}\text { Interaction } \\
\text { with } \\
\text { friends }\end{array}$ & $\begin{array}{l}\text { Affective } \\
\text { and social } \\
\text { skills }\end{array}$ & $\begin{array}{c}\text { Friendly } \\
\text { withdrawal } \\
\text { and } \\
\text { avoidance } \\
\end{array}$ & $\begin{array}{l}\text { Emotional } \\
\text { emptiness }\end{array}$ & Overall \\
\hline $\begin{array}{l}\text { Self-awareness } \\
\text { and confidence in } \\
\text { others' } \\
\text { acceptance. }\end{array}$ & 1 & & & & & & & \\
\hline $\begin{array}{l}\text { Self-confidence. } \\
\text { Family }\end{array}$ & $.593 * *$ & 1 & & & & & & \\
\hline $\begin{array}{l}\text { containment and } \\
\text { communication. }\end{array}$ & $.625^{* *}$ & $.522 * *$ & 1 & & & & & \\
\hline $\begin{array}{l}\text { Interaction with } \\
\text { friends }\end{array}$ & $.669^{* *}$ & $.561 * *$ & $.736 * *$ & 1 & & & & \\
\hline $\begin{array}{l}\text { Affective and } \\
\text { social skills. } \\
\text { Friendly }\end{array}$ & $.711 * *$ & $.672 * *$ & $.667 * *$ & $.677 * *$ & 1 & & & \\
\hline $\begin{array}{c}\text { withdrawal and } \\
\text { avoidance. }\end{array}$ & $.657 * *$ & $.637 * *$ & $.577 * *$ & $.506^{* *}$ & $.789 * *$ & 1 & & \\
\hline $\begin{array}{l}\text { Emotional } \\
\text { emptiness. }\end{array}$ & $.723 * *$ & $.603 * *$ & $.777 * *$ & $.589 * *$ & $.815^{* *}$ & $.823 * *$ & 1 & \\
\hline Overall. & $.837 * *$ & $.776^{* *}$ & $.834 * *$ & $.818^{* *}$ & $.911 * *$ & $.830 * *$ & $.891 * *$ & 1 \\
\hline
\end{tabular}

Note. ${ }^{* *} \mathrm{p}<.01$.

It is inferred from Tables 3 and 4 that all the correlation coefficients and item-total correlations were suitable and acceptable; therefore, none of the items was removed.

Test Reliability. To calculate the Social Isolation Test's reliability, the authors used Cronbach's alpha to compute the internal consistency of the pilot sample's responses. The test was retested after an interval of two weeks to verify test-retest reliability. Pearson's correlations of the estimates of the pilot sample over the two periods are shown in Table 5.

Table 5. The internal consistency and test-retest reliability of the social isolation test

\begin{tabular}{lcc}
\hline Dimension & Internal consistency & Test-retest reliability \\
\hline Self-awareness and confidence in others' acceptance & 0.87 & 0.89 \\
Self-confidence & 0.86 & 0.90 \\
Family containment and communication & 0.88 & 0.92 \\
Interaction with friends & 0.76 & 0.81 \\
Affective and social skills & 0.82 & 0.87 \\
Friendly withdrawal and avoidance & 0.74 & 0.87 \\
Emotional emptiness & 0.80 & 0.83 \\
Overall & 0.92 & 0.93 \\
\hline
\end{tabular}

\subsection{Procedures}

The test-retest reliability and validity of the two tests were ensured. Participants' demographic information (i.e., name, sex, and academic level) appeared at the beginning of the questionnaires, followed by the test items. The sample was selected using a stratified random cluster technique. Participants indicated the degree of their agreement with each item of the two tests. Responses were computed for each test. Informed consent was obtained from the relevant authorities (king saud university, Ministry of education) to apply the questionnaires of the study.

\subsection{Statistical Analysis}

The authors computed means, standard deviations, Pearson (Spearman) correlations, z-value, a regression 
analysis, and an analysis of variance (ANOVA) to address the study questions.

\section{Results}

To answer the first question, "Are there significant differences $(\alpha \leqslant .05)$ in affective isolation per sex and academic level, and does the interaction between sex and academic level have a statistically significant impact on affective isolation?", the means and standard deviations of affective isolation based on sex and academic level were computed and were clearly apparent (Table 6).

Table 6. Means and standard deviations of affective isolation based on sex and academic level

\begin{tabular}{lcccc}
\hline Sex & Academic level & M & SD & Number \\
\hline \multirow{3}{*}{ Male } & First-year & 3.18 & .613 & 114 \\
& Fourth-year & 3.35 & .598 & 107 \\
& Total & 3.26 & .610 & 221 \\
Female & First-year & 3.14 & .578 & 115 \\
& Fourth-year & 3.07 & .486 & 121 \\
& Total & 3.10 & .533 & 236 \\
Overall & First-year & 3.16 & .595 & 229 \\
& Fourth-year & 3.20 & .558 & 228 \\
& Total & 3.18 & .577 & 457 \\
\hline
\end{tabular}

To determine significance of the means, a two-way ANOVA was conducted (Table 7).

Table 7. An analysis of variance of the impact of sex and academic level and their interaction on levels of affective isolation

\begin{tabular}{lccccc}
\hline Source of variance & $\begin{array}{c}\text { Sum of } \\
\text { squares }\end{array}$ & $\begin{array}{c}\text { Degree of } \\
\text { freedom }\end{array}$ & $\begin{array}{c}\text { Means } \\
\text { squared }\end{array}$ & F & Sig. \\
\hline Sex & 3.057 & 1 & 3.057 & 9.441 & .002 \\
Academic level & .325 & 1 & 325. & 1.003 & .317 \\
Sex $\times$ academic level & 1.629 & 1 & 1.629 & 5.030 & .025 \\
Error & 146.694 & 453 & 324. & & \\
Overall & 151.591 & 456 & & & \\
\hline
\end{tabular}

Table 7 shows that there was a significant difference $(\alpha=.05)$ per sex, with men scoring higher than women; however, no statistical difference $(\alpha=.05)$ was shown per academic level. Moreover, the results showed a significant difference $(\alpha=.05)$ in affective isolation, based on the interaction between sex and academic level (Figure 1). Specifically, fourth-year male students and first-year female students obtained higher scores than did their first-year and fourth-year counterparts, respectively.

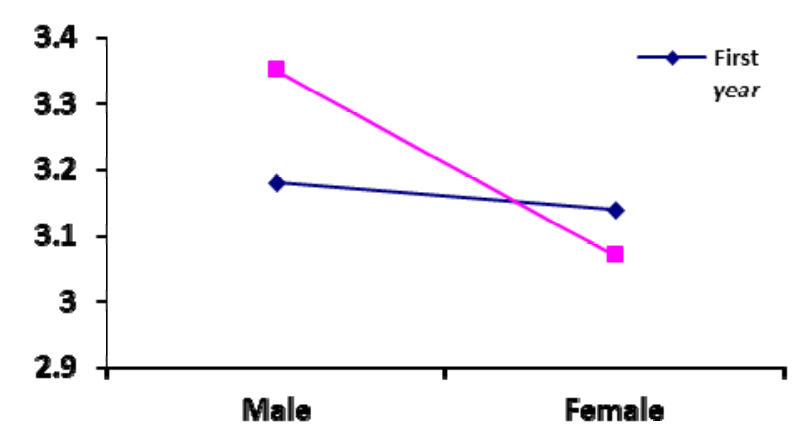

Figure 1. Interaction between academic level, sex, and affective isolation

To answer the second question, "What is the nature of the relationship between affective isolation and overall 
social isolation and its dimensions and are there significant differences $(\alpha=.05)$ in the relationship per sex and academic level?", Pearson's correlation coefficient was computed for affective and social isolation (Table 8).

Table 8. Pearson's correlation coefficient of affective and social isolation and its dimensions

\begin{tabular}{|c|c|c|c|}
\hline Affective Isolation Test and its dimensions & Pearson's correlation coefficient (r) & Sig. & No. \\
\hline Self-awareness and confidence in others' acceptance & -.034 & .466 & 457 \\
\hline Self-confidence & $-.125 * *$ & .008 & 457 \\
\hline Family containment and communication & $-.162 * *$ & .001 & 457 \\
\hline Interaction with friends & $-.673 * *$ & .000 & 457 \\
\hline Affective and social skills & -.069 & .139 & 457 \\
\hline Friendly withdrawal and avoidance & $.441 * *$ & .000 & 457 \\
\hline Emotional emptiness & $.250 * *$ & .000 & 457 \\
\hline Overall & $-.237 * *$ & .000 & 457 \\
\hline
\end{tabular}

Note. ${ }^{* *} \mathrm{p}<.01$.

As shown in Table 8, the differences between self-awareness, confidence in others' acceptance, and affective and social skills within affective isolation were not significant. There was a significant negative correlation between the social isolation dimensions of self-confidence, family containment and communication, and interaction with friends for social isolation. A significant negative correlation was found between overall social affection and overall affective isolation.

To answer the third question, "Does affective isolation contribute towards the prediction of social isolation?", the authors conducted a regression analysis to compute the effect of affective isolation on social isolation (Table 9). A significant negative effect of affective isolation on social isolation was found.

Table 9. Regression analysis on affective isolation's impact on social isolation

\begin{tabular}{cccccccc}
\hline $\begin{array}{c}\text { Independent } \\
\text { variable }\end{array}$ & $\mathrm{B}$ & $\mathrm{t}$ & $\mathrm{Sig}$ & Correlation & $\begin{array}{c}\text { Explained } \\
\text { variance }\end{array}$ & $\mathrm{F}$ & $\mathrm{Sig}$. \\
\hline Social isolation & -.067 & 5.200 & $001 .>$ & 237. & 056.0 & 27.044 & $001 .>$ \\
\hline
\end{tabular}

Dependent variable: affective isolation.

\section{Discussion}

Maslow and colleagues believed that affective isolation is an individual's inability to satisfy his or her needs and self-actualization, due to the harsh and threatening environment that does not allow for natural development and growth. If these needs are not satisfied appropriately, the situation becomes stressful, and the individual's psychological balance breaks down (Maslow, Frager, \& Cox, 1970). The stress that individuals are confronted with, such as life difficulties, scarcity of resources, and loss of psychological security, reinforces feelings of inferiority and leads to feelings of isolation, constant failure, and despair, and creates many psychological and social problems (Bargh \& Morsella, 2010).

A higher amount of affective isolation among males is attributed to their physiological make-up and biological functioning (Rook, 1985). Males have been reported to have poor adjustment, and to be extremely loyal to their clans or territories; these reportedly precipitate their maladjustment and tendency to detach themselves from the environments that they live in. Fromm (cited in Katz, Boggiano, \& Silvern (1993) stresses that feelings of affective isolation are a natural human characteristic that accompanies development. Feelings of affective isolation represent a painful personal experience that individuals are confronted with at a certain stage of their lives and emerge at all life stages. Everyone experiences affective isolation, but in different degrees and at various times. However, it reaches its peak during adolescence; adolescents are considered the largest group to be affected by affective isolation (Fenz \& Constantinou, 2008).

Certainly, low levels of self-confidence, less containment and communication, and decreased interactions with friends increases a predisposition towards affective and social isolation. Insults, being teased, low self-esteem, and perceived lack of social acceptance among youths all represent the emotional neglect that stimulates isolation (Haines et al., 1993). Life's complexities and modern-day problems have resulted in the emergence of 
technological, social, and educational outputs that have changed standards for the family structure and the conceptualization of the community structure. The mechanisms of social networking, standards of family education, and the concept of family have changed dramatically. Similarly, our child-rearing methods and ways of communicating with friends have changed. Life requirements and the pace of global development have resulted in different standards altogether. The feelings of failure, frustration, and stress that follow from failing to achieve one's aspirations and desires negatively affect the family unit, leading to disruption of communication between family members (Profitt, 1999).

The positive relationships between the level of affective isolation, containment and withdrawal, and emotional emptiness are attributed to negative aspects of the personalities of isolated individuals, such as withdrawal, lack of assertiveness, waiving one's rights, a lack of openness and severe secrecy, cautiousness, and vulnerability (Caspi et al., 2006). Adler (cited in Mohammed, 2000) attributes feelings of affective isolation to emotional deprivation, such as lack of love, affection, and encouragement, which leads to feelings of inferiority and social withdrawal.

According to Freud, affective isolation is a process of dissonance within the individual's psyche (id, ego, and super ego), which leads to maladjustment with the self and the social environment. Social and affective isolation are considered a defensive psychological mechanism that protects the personality from emerging threats from the social environment and individuals' risk of rejection, whether it is real or imagined (Jung, 2015). Some individuals experience affective isolation because they lack the "id" skills that enable engagement in social relations, cannot follow standards and act in accordance to them, and engage in a very complicated social pattern. Others accept social isolation culture willingly due to active rejection of the predominant culture and its standards, or the pursuit of goals that require periods of isolation and being away from others. Therefore, being socially isolated reflects individuals' voluntary or forced isolation (Cutrona, 1982).

\subsection{Limitations}

This study had some limitations that inhibit the generalizability of the findings. First, the sample only comprises first- and fourth-year undergraduate students enrolled at King Saud University. Second, we used psychometric tools (i.e., the Affective Isolation Test and the Social Isolation Test). Lastly, we only examined participants during a specific period (i.e., second semester of the 2015/2016 academic year).

\subsection{Implications and Future Directions}

Considering these results, we suggest a need for more studies concerning affective isolation that further address the effects of age and sex. Researchers should develop training programs that teach individuals how to avoid isolation. Studies exploring the correlations between affective and social isolation that incorporate different variables within different social contexts are also needed.

\section{Compliance with Ethical Standards}

This study was conducted with approval from the responsible ethics committee (King Saud University, Ministry of education) and in accordance with national law and the Helsinki Declaration of 1975 (in its current, revised form). Informed consent was obtained from all participants.

\section{Acknowledgments}

We extend our appreciation to the Deanship of Scientific Research, King Saud University for funding this work through the Undergraduate Student's Research Support Program (project no. USRSP-15-20).

\section{References}

Adler, A. (2013). The practice and theory of individual psychology (Vol. 133). Routledge.

Al-Ghamdi, Lotfi. (2011). The 10th Strategic Plan in the Saudi Ministry of Education and the Problems Facing the Application as Preceived by Educational Districts Directors (Unpublished MD thesis). Yarmouk University, Irbid.

Bargh, J. A., \& Morsella, E. (2010). Unconscious behavioral guidance systems. Then a miracle occurs: Focusing on behavior in social psychological theory and research (pp. 89-118).

Bhugra, D. (2004). Migration and mental health. Acta Psychiatrica Scandinavica, 109(4), 243-258. https://doi.org/10.1046/j.0001-690X.2003.00246.X

Caspi, A., Harrington, H., Moffitt, T. E., Milne, B. J., \& Poulton, R. (2006). Socially isolated children 20 years later: Risk of cardiovascular disease. Archives of Pediatrics \& Adolescent Medicine, 160(8), 805-811. https://doi.org/10.1001/archpedi.160.8.805 
Chan, Y. F., Dennis, M. L., \& Funk, R. R. (2008). Prevalence and comorbidity of major internalizing and externalizing problems among adolescents and adults presenting to substance abuse treatment. Journal of Substance Abuse Treatment, 34(1), 14-24. https://doi.org/10.1016/j.jsat.2006.12.031

Coyle, C. E. (2014). The effects of loneliness and social isolation on hypertension in later life: Including risk, diagnosis and management of the chronic condition. University of Massachusetts Boston.

Cutrona, C. E. (1982). Transition to college: Loneliness and the process of social adjustment. Loneliness: A Sourcebook of Current Theory, Research, and Therapy, 36, 291-309.

Dugan, E., \& Kivett, V. R. (1994). The importance of emotional and social isolation to loneliness among very old rural adults. The Gerontologist, 34(3), 340-346. https://doi.org/10.1093/geront/34.3.340

Fenz, D. M., \& Constantinou, M. C. (2008). Spherical sliding isolation bearings with adaptive behavior: Theory. Earthquake Engineering and Structural Dynamics, 37(2), 163-183. https://doi.org/10.1002/eqe.751

Frampton, R., \& Thomas, K. (2011). The effectiveness of isolation timeouts for students with severe emotional disabilities attending a therapeutic day school. Dissertations, Paper 226. Retrieved from $\mathrm{http}: / /$ ecommons.luc.edu/cgi/viewcontent.cgi?article=1225\&context=luc_diss

Grippo, A. J., Lamb, D. G., Carter, C. S., \& Porges, S. W. (2007). Social isolation disrupts autonomic regulation of the heart and influences negative affective behaviors. Biological Psychiatry, 62(10), 1162-1170. https://doi.org/10.1016/j.biopsych.2007.04.011

Haines, D. A., Scalise, J. J., \& Ginter, E. J. (1993). Relationship of loneliness and its affective elements to self-esteem. Psychological Reports, 73, 479-482. https://doi.org/10.2466/pr0.1993.73.2.479

Hall-Lande, J. A., Eisenberg, M. E., Christenson, S. L., \& Neumark-Sztainer, D. (2007). Social isolation, psychological health, and protective factors in adolescence. Adolescence, 42(166), 265.

Heaven, P. C. (2001). The social psychology of adolescence. Palgrave Macmillan. https://doi.org/10.1007/978-1-137-10743-5

Hollos, M., \& Cowan, P. A. (1973). Social isolation and cognitive development: Logical operations and role-taking abilities in three Norwegian social settings. Child Development, 630-641. https://doi.org/10.2307/1128022

Jahoda, M. (1958). Current concepts of positive mental health.

Jung, C. G. (2015). Freud and psychoanalysis (Vol. 4). Routledge.

Katz, P. A., Boggiano, A., \& Silvern, L. (1993). Theories of female personality. Psychology of women: A handbook of issues and theories (pp. 247-280).

Khader, A. (2009). Affective isolation and its relationship with the personality style among the university students. Anbar Humanities University Journal, 4(3), 214-220.

Maslow, A. H., Frager, R., \& Cox, R. (1970). Motivation and personality (Vol. 2, pp. 1887-1904). In J. Fadiman, \& C. McReynolds (Eds.). New York: Harper \& Row.

Mikulincer, M., \& Florian, V. (1995). Appraisal of and coping with a real-life stressful situation: The contribution of attachment styles. Personality and Social Psychology Bulletin, 21(4), 406-414. https://doi.org/10.1177/0146167295214011

Platt, L. (2009). Social activity, social isolation and ethnicity. The Sociological Review, 57(4), 670-702. https://doi.org/10.1111/j.1467-954X.2009.01867.x

Profitt, N. J. (1999). Book review: Battered women, children, and welfare reform: The ties that bind. Affilia, 14(4), 491-493. https://doi.org/10.1177/088610999901400408

Rook, K. S. (1985). The functions of social bonds: Perspectives from research on social support, loneliness and social isolation. In Social support: Theory, research and applications (pp. 243-267). Springer Netherlands. https://doi.org/10.1007/978-94-009-5115-0_14

Saleh, N. (2012). The social isolation index. Psychological Counseling Journal, 33, 500-529.

Sanders, C. E., Field, T. M., Miguel, D., \& Kaplan, M. (2000). The relationship of Internet use to depression and social isolation among adolescents. Adolescence, 35(138), 237.

Shaver, K. G., \& Scott, L. R. (1991). Person, process, choice: The psychology of new venture creation. Entrepreneurship Theory and Practice, 16(2), 23-45.

Wedding, D. (2010). Current psychotherapies. In Corsini encyclopedia of psychology. John Wiley \& Sons, Inc. 
https://doi.org/10.1002/9780470479216.corpsy0248

Weiss, R. S. (1973). Loneliness: The experience of emotional and social isolation.

Williamson, D. (2004). Research reveals social isolation, boosts teen girls' suicide thoughts. Retrieved from http://sph.unc.edu/research-reveals-social-isolation-boosts-teen-girls-suicide-thoughts/

\section{Copyrights}

Copyright for this article is retained by the author(s), with first publication rights granted to the journal.

This is an open-access article distributed under the terms and conditions of the Creative Commons Attribution license (http://creativecommons.org/licenses/by/4.0/). 